\title{
Modelling youth pregnancy in continental Portugal through geographically weighted regression
}

\author{
João David, Pedro Cabral \\ NOVA Information Management School, NOVA University of Lisbon, Lisbon, Portugal
}

\begin{abstract}
Youth pregnancy, a global public health problem with important social, educational and economic impact, has mostly been studied in the least developed countries. However, this condition also affects the industrialized countries. This article presents a youth pregnancy study at the municipality level in continental Portugal based on geographically weighted regression. The results indicate that youth pregnancy rates can be explained by several variables: i) proportion (\%) of social security beneficiaries; ii) number of households without amenities; iii) the rate of those prematurely leaving school; iv) the unemployment rates of youths and females, ceteris paribus. In addition, it was found that the beneficiaries of social security had a higher impact on youth pregnancy in the southern part of the country, and in the Centre too; that households without amenities had a higher impact along the central coast and in the South; that rates of those leaving school prematurely had a higher influence in the North and the Interior than in the rest of the country; and that youth and female unem-
\end{abstract}

Correspondence: João David, NOVA Information Management School, NOVA University of Lisbon, Campolide Campus, 1070-312 Lisbon, Portugal.

Tel.: +351.213.828.610.

E-mail: jcdavid@novaims.unl.pt

Key words: Youth pregnancy; Spatial modelling; Geographically weighted regression; Non-stationarity; Geographical information systems; Portugal.

See online Appendix for an additional Table.

Contributions: the authors contributed equally.

Conflict of interest: the authors declare no potential conflict of interest.

Funding: none.

Received for publication: 27 February 2018.

Revision received: 26 January 2019.

Accepted for publication: 26 January 2019.

CC Copyright J. David and P. Cabralet al., 2019

Licensee PAGEPress, Italy

Geospatial Health 2019; 14:680

doi:10.4081/gh.2019.680

This article is distributed under the terms of the Creative Commons Attribution Noncommercial License (CC BY-NC 4.0) which permits any noncommercial use, distribution, and reproduction in any medium, provided the original author(s) and source are credited. ployment rates were more widespread in the Centre, particularly along the coast. Overall, the model identified a strong association of explanatory variables with youth pregnancy rates in the country as a whole, except in the Porto metropolitan area. These findings may help health planners to define policies to mitigate this important social problem.

\section{Introduction}

Youth pregnancy is an important social problem that changes the lifestyle of both parents and the family structure in general. Having babies when young was previously considered normal, even the best time to be pregnant, but nowadays it has become regarded as too uncommon, i.e. an entirely disproportionate structure in the population as a whole, particularly in developed societies (Martinez et al., 2011).

Social disadvantage and exclusion are contributing factors to young parenthood (Harden et al., 2006). Researchers connect greater teenage pregnancy rates with households having socioeconomic troubles and with low education levels (Araújo Pedrosa et al., 2011; Coelho et al., 2013). Behind the raised risk for youth pregnancy incidence there is often deprivation, particularly with respect to economy, educational situation (school failure), literacy and employment (Araújo Pedrosa et al., 2011). Adolescents in perinatal circumstances are underserved and marginalized, which reinforces the significant role of gender equality with regard to adolescent childbearing (Siegel and Brandon, 2014; Decker et al., 2016). Disrupted family structure is another consistently related risk factor for early childbearing (Imamura et al., 2007) following from the fact that homeless young women belong to a distinguished population peculiarly exposed to this risk (Thompson et $a l .$, 2008). Besides, pregnant teens experience increased levels of partner violence with abandonment or unstable home environments leading to higher use of tobacco, alcohol and drugs compared to other teens (Leftwich and Alves, 2017). Exposure to illicit drugs and alcohol during teenage years has been shown to be connected with the involvement in unsafe sex and early pregnancy (Odgers et al., 2008). At the individual level, dislike of school, emotional instability and personal expectations of adolescent parenthood are among the factors provoking a higher individual vulnerability, often ending in adolescent pregnancy (Araújo Pedrosa et al., 2011). Female adolescents coming from high-risk groups have an increased risk of becoming teenage mothers (Christoffersen and Azhar, 2008), while teenagers living in communities characterized by better economical and social services and opportunities are more likely to delay childbearing (Shoff and Yang, 2012).

Youth pregnancy is considered a public health problem due to the associated negative effects and complications. While the 
mother can experience maternal depression, hypertensive disorders of pregnancy, abortion or preterm delivery, the child may be affected by birth trauma, such as infant/perinatal mortality and preeclampsia, often resulting in impaired neurocognitive development (Baker et al., 2007; Azevedo et al., 2015; Leftwich and Alves, 2017). The new-born's predisposition to infections and other effects associated with low birth weight can result in serious complications with regard to her/his future development (Martinez et al., 2011). According to the World Health Organization (WHO), pregnancy and childbirth problems are commonly the primary cause of death among 15-19 olds in a global perspective (WHO, 2014). Those most susceptible to early pregnancy are adolescents, who are less ready to nourish, educate and raise a child (WHO, 2005). In addition, children of teenage mothers are more likely to become teenage parents themselves (Cook and Cameron, 2015). Yet, the relationship between an older sister's teenage pregnancy and a younger sister's teenage pregnancy is stronger than that between a mother's teenage childbearing and a younger daughter's teenage pregnancy (Wall-Wieler et al., 2016). Pregnant adolescents are also at an increased risk having another child (Siegel and Brandon, 2014). Depression, abortion, lower education and lack of contraceptive use have been pointed out as the major causes (Maravilla et al., 2017), while there is no evidence that those factors are different from the first pregnancy (Rowlands, 2010). Importantly, the fertility rate among poor adolescents is much higher than in adolescents with better economic conditions (Singh et al., 2001; ChildTrends, 2016). It is generally assumed that most of youth pregnancies are unintentional and that they therefore can lead to child maltreatment (Guterman, 2015; Leftwich and Alves, 2017). On the other hand, the desire for pregnancy suggests a higher risk for subsequent pregnancy confirming the link between adolescent pregnancy desire and pregnancy over time (Sipsma et al., 2011). This attests that childbirth can also be planned and wanted by adolescents (WHO, 2014). Nevertheless, during the last 20 years, adolescent abortion and youth pregnancy rates have declined considerably due to increased use of contraception as well as decreased and late initiation of sexual activities. Part of the explanation is the that access to family planning services and comprehensive sexual health education programmes have been effective strategies (Darroch and Singh, 1999; Kohler et al., 2008; Washington State Department of Health, 2014; Lindberg et al., 2016; Singh et al., 2018). Bangladesh stands for the greatest change, where the rate of unintentional pregnancy has decreased from $31.5 \%$ to $19.7 \%$ in the period 1996/97-2011 (Decker et al., 2016). However, the struggle against this problem is not over (Mendes et al., 2014). According to the United Nations Populations Fund (UNFPA, 2013), Africa holds the topmost youth fecundity rates and faces major economic, social and political difficulties. Furthermore, adolescent pregnancy and child marriage are connected in West and Central Africa (Fenn et al., 2015), while in Latin American countries, e.g., Colombia, education is pointed out as the main subject to tackle teenage pregnancy (Daniels, 2015). In Russia, more than half of youth pregnancies are interrupted (Panova et al., 2016), while the United States (US) has nonrandom, high clusters of elevated teenage birth rates (Amin et al., 2017) underlining that knowledge gaps and misinformation about birth control methods persist, even in the US (Shartzer et al., 2016).

Progress in at least six of the Millennium Development Goals - now replaced by the Sustainable Development Goals (SDGs) were directly and negatively affected by youth pregnancies
(UNFPA, 2013). Even so, improvements are being made in lower and middle-income countries. One of those enhancements includes governmental programs enabling pregnant girls to continue their education after having given birth, a measure frequently taken on by several nations (UNICEF, 2004; CCITWG, 2009; Nkosha et al., 2013; Birungi et al., 2015). Likewise, some other encouraging outcomes are found around the globe, e.g., in Ukraine, where access to contraception has reduced abortions by $2 / 3$ (UNFPA, 2013); in Kenya, where free school uniforms increased enrolments and lowered pregnancy rates by 17 per cent (UNFPA, 2013); or India, where a programme aiming at higher contraception use specifically targeting young married women was similarly successful (UNFPA, 2013). With regard to the European Union, applying a joint initiative to reduce teenage pregnancy is expected to provide Member States with a common measurement framework and common targets (Fronteira et al., 2009).

Existing research highlights the socioeconomic status and behavioural variables correlated with pregnancy at school age (Berry et al., 2000; Shoff and Yang, 2012; Shoff et al., 2012). Yet, the analysis of this phenomenon needs to be extended to a geographic level to be better understood. The lack of a spatial dimension in youth pregnancy studies is concerning because certain aspects are ignored, such as the fact that adolescents living in disfavoured regions have fewer opportunities, which may lead to a lower incentive to prevent the birth of a child (Shoff and Yang, 2012). This is supported by the suggestion that distance to family planning clinics matters with respect to attenuating risky sexual activities among older adolescents (Bersamin et al., 2011). Therefore, the characteristics of certain places may influence behaviour, values and attitudes, which ensure that populations should be considered within a geographical context (Roza and Martinez, 2015). Despite some risk factors that cannot be controlled or modified, others must be processed to reduce the vulnerability of exposure in this regard (Blake and Bentov, 2001).

In continental Portugal, the geographical dimension of health is well promoted and implemented. The contribution from geographers and geographical information systems specialists to health scientific research is increasing and significant progress has already been achieved (Santana et al., 2014). Suicide, diabetes, cancer and premature births have been studied applying spatial analysis (Miranda et al., 2014; Santana et al., 2014, 2015; Costa et al., 2015; Roquette et al., 2017). In this context, it is worthwhile to highlight the GeoHealthS project, which aims to evaluate the health of the Portuguese population over the last 20 years through the construction, application and availability of a population health index at the municipal level. However, major actual ecological and statistical studies about youth pregnancy in Portugal do not include spatial analysis, which is vital to obtain geospatial knowledge (Singh and Darroch, 2000; Figueiredo et al., 2005, 2006a, 2006b; Araújo-Pedrosa et al., 2011; Fonseca et al., 2012; Figueiredo et al., 2014; Mendes and Castelo-Branco, 2014; Pires et al., 2014; Fonseca and Almeida Santos, 2015).

In the year 2000, Portugal was identified as part of a western European cluster with the moderate rate of 20-34 births per 1000 women aged 15-19 (Singh and Darroch, 2000). Despite the existence of legal instruments related to sexual education and youth pregnancy, local non-governmental organizations, schools, institutions and associations, such as the Family Planning Association maintain an active role dealing with youth pregnancy issues.

This study aims to model the spatial patterns of youth pregnancies in continental Portugal in the period 2010-2015 using geo- 
graphically weighted regression (GWR). Specifically, it aims to answer the following questions: i) what are the factors and relationships that may explain youth pregnancy rates? and ii) how do they vary across space? Based on the literature concerned with this area of research, we introduce the hypothesis that youth pregnancy rates may be associated with geographical aspects of the economic, social and educational conditions. A better understanding of youth pregnancy with regard to geographical distribution may contribute to the design of more effective preventive strategies that could mitigate its occurrence.

\section{Materials and Methods}

\section{Study area and data}

The study area comprises continental Portugal, adopting the municipality (concelho) as the statistical unit. There are 278 municipalities in the study region with 10,047,621 inhabitants according to the census 2011 (INE, 2011). This analysis focuses on the mainland Portugal for two reasons. First, we believe that the two autonomous regions of Portugal - the islands of Madeira and Azores - represent a different and specific actuality concerning youth pregnancy. Thus, taking geography into consideration, they would be better studied separately. Second, GWR uses a kernel density approach that places different weights on the various observations and the results are sensitive to the bandwidth of this weighting function. Including only the municipalities of the mainland would better fit the adaptive kernel rather than including distant municipalities, such as those located in Madeira and Azores.

The dependent variable corresponds to the youth pregnancy rates for each municipality. We used the number of live births by mothers aged from 15 to 19 years old recorded in continental Portugal in the period 2010-2015, divided by the geometrical mean of women with the same age and in the same period. To obtain the rate, those values were multiplied by 100 . We also considered the municipality where the mother lives, not the municipality where the birth took place. The independent variables were selected according to four criteria: i) potential ability to explain youth pregnancy rates; ii) compatibility to previous literature; iii) data availability; and iv) data redundancy. Accordingly, three major groups of independent variables were studied: demographic; socioeconomic; and geographic parameters. A total of 35 potential explanatory variables (detailed in the Appendix) were taken into account. Practically, all of them were gathered from the Portuguese National Statistics Institute and PORDATA websites. The latter is the contemporary Portuguese database of official and certified statistics. Two additional potential geographic predictor variables were included: area representing the expanse of each municipality in $\mathrm{m}^{2}$, and distance to nearest district capital. The collected data were averaged for the available range of years for each variable, i.e. from the Census 2011 to the latest available year (2015). Value 0 was excluded in all averages to avoid bias.

\section{Statistical approach}

The methodological framework included four phases: i) Exploratory spatial data analysis; ii) Ordinary Least Squares (OLS) and GWR modelling; iii) Data pre-processing and model implementation; and iv) Model performance assessment.

\section{Exploratory spatial data analysis}

An hotspot analysis was performed using the Getis-Ord Gi* statistics (Longley and Batty, 1996) to understand if either high or low values of the dependent variable clustered spatially (Mitchell, 2005). The conceptualization of spatial relationships was determined using a fixed Euclidean distance band of $30,753 \mathrm{~m}$, which was the value of the maximum peak of spatial autocorrelation. The false discovery rate, which considers spatial dependence and local isolation of multiple tests, was applied with a $95 \%$ confidence level. This procedure potentially reduces the critical P-value thresholds to account for multiple testing and spatial dependency (ESRI, 2017). With the same parameters, we ran a cluster and outlier analysis according to Anselin (1995). As a final step at this stage, we also selected the variables bearing a linear correlation with the dependent variable, excluding those that did not behave in this way.

\section{Ordinary least squares and geographically weighted regression modelling}

OLS estimates the unknown parameters in a linear regression model minimizing the sum of the squares of the differences between the observed number of youth pregnancy rates and those predicted by a linear function of a set of explanatory variables. GWR extends the OLS approach by incorporating spatial dependence through a kernel bandwidth (Brunsdon et al., 1998). GWR is very sensitive with regard to the kernel bandwidth, i.e. a small bandwidth generally generates localized estimations ( $\mathrm{Su}$ et al., 2014). The GWR was modelled with the same predictors used in the final OLS. As the points of the municipalities were not regularly clustered, an adaptive kernel using a near-Gaussian weighting function was selected based on the corrected Akaike Information Criterion (AICc) (Akaike, 1974; ESRI, 2017).

\section{Data pre-processing and model implementation}

For ease of comparison and interpretation, a $\log 2$ transformation was applied to all variables (Manikandan, 2010). We evaluated multiple possible combinations of candidate explanatory variables looking for the model that could best explain youth pregnancy in the study context without disrupting OLS/GWR assumptions. The following variables were statistically significant for the global regression model: i) distance to the nearest district capital; ii) illiteracy rate; iii) rate of prematurely leaving school; iv) youth and female unemployment rate; v) number of households without amenities; vi) number of family planning appointments; and vii) abortion rate. The variance inflation factor (VIF) was determined to assess multicollinearity among the different variables - only variables with a $\mathrm{VIF}<1.08$ were kept. A stepwise procedure was used to enter the remaining variables for OLS using the T-test statistic (SAS Institute, 2010) to find the estimated coefficients. Only the variables that passed these criteria were later used as input variables for the GWR. The Joint Wald statistic (Wald, 1943), Koenker statistic (Koenker, 1981) and Jarque-Bera statistic (Jarque and Bera, 1980, 1987) were used to test the pertinence of using GWR, i.e. the significance and stationarity of the global model (Ivajnšič et al., 2014; Su et al., 2014). The OLS and GWR were implemented using ESRI ArcGIS 10.6 software (ESRI, 2017).

\section{Model comparison}

The AICc and adjusted $\mathrm{R}^{2}$ were used to describe model performance. A low AICc and a high adjusted $\mathrm{R}^{2}$ value indicate preferen- 
tial model performance (Fotheringham et al., 2002). The significance of the comparisons was carried out through the computation of the F-test (Fotheringham et al., 2002). The Moran's I was determined to assess the existence of spatial autocorrelation of the model residuals, i.e. if significant spatial autocorrelation is found, the randomly distributed assumption has been violated (Fotheringham et al., 2002).

\section{Results}

In the referenced period, a total of 17,091 births by teenage mothers were recorded in continental Portugal (Figure 1). The average number of such births per municipality was 61 between year 2010 and 2015. Alcoutim in the Algarve region was the only municipality with no such births at all, while Lisbon municipality had the highest value with 1,232 births, although nearby Sintra had a higher population of youths (10-19). Despite the large range of values, $75 \%$ of the municipalities had about 60 births on average. In general, the metropolitan areas and some municipalities in the South showed the highest density of births by teenage mothers. A total of 112 municipalities had at least one birth by a mother aged from 10 to 14 , corresponding to 291 births by mothers of that age (Figure 2). The dependent variable is mapped in Figure 3, which shows that the highest concentration of values was located in the interior of the country, and from the Centre to the South. The capital's metropolitan area showed a high youth pregnancy rates with the exception of two municipalities. The same can be said for the Algarve region, in the South. Low rates were seen in some locations in the North and the Centre. With the conceptual spatial relationship set as a fixed distance band of $30,753 \mathrm{~m}$, the Local Moran's $I$ statistic spotted positive spatial autocorrelation with low-value clusters in the central region. High-value clusters were observed in the Lisbon metropolitan area and in several other administrative units located in the Alentejo region (Figure 4). Another municipality with dissimilar values with regard to its neighbouring territories was identified north of Lisbon on the country's border to Spain. Finally, the Getis-Ord Gi* method identified both coldspots and hotspots (Figure 5). Not surprisingly, those clusters were formed at the same locations shown by the previous analysis. Nonetheless, Getis-Ord Gi* mapped a new coldspot in the North.

The variables of the highest explicatory value with respect to the increase of youth pregnancy rates in continental Portugal were Social Security beneficiaries, households without amenities, those leaving school prematurely and youth and female unemployment, ceteris paribus. These predictors exhibited neither global nor local multicollinearity. Other independent variables, such as the abortion rate, were strong candidates, but could not be confirmed as predictor variables as they all failed when the Jacque-Bera statistic was

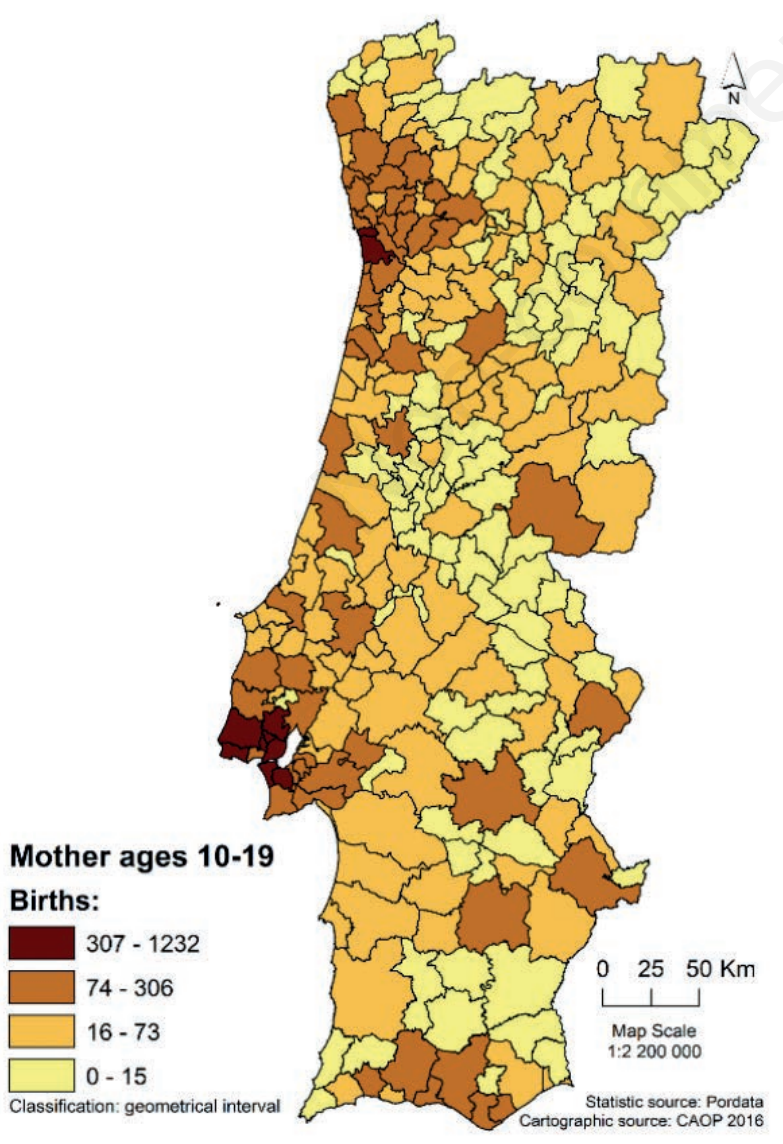

Figure 1. Births by mothers aged 10-19 years.

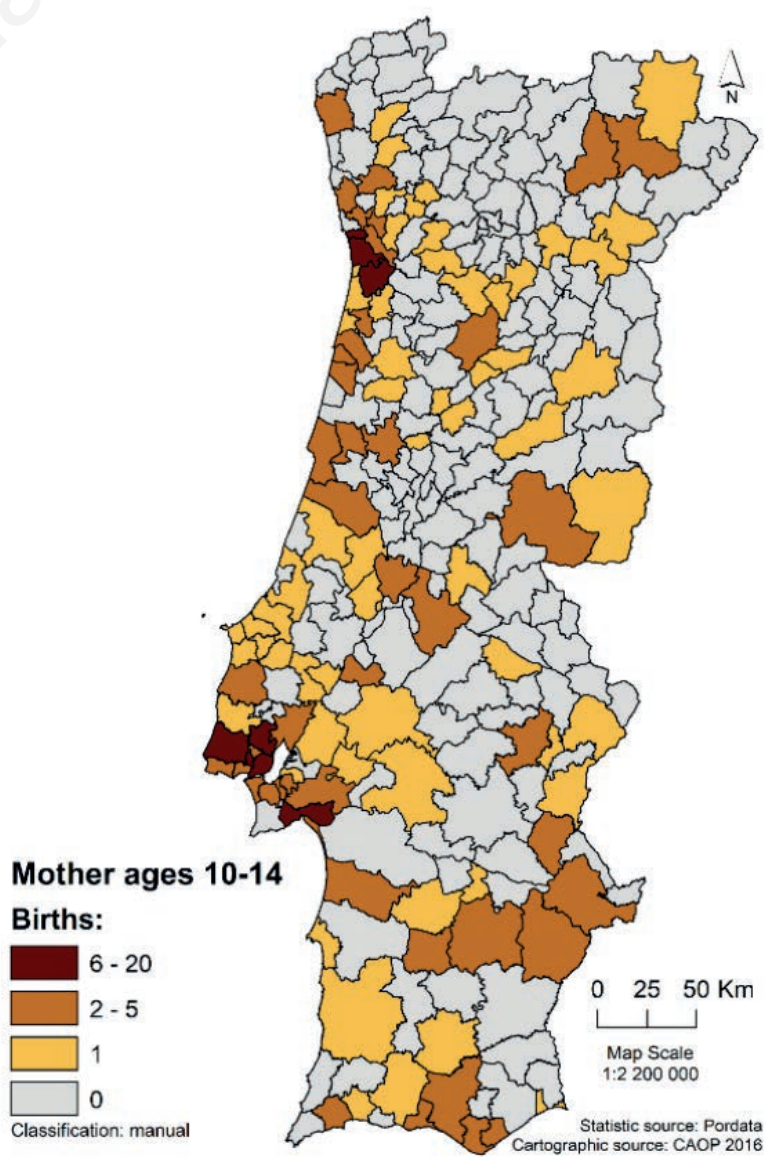

Figure 2. Births by mothers aged 10-14 years. 
applied. In the global context, the model confirms the regression assumptions (Table 1), except for the spatial autocorrelation residuals. This is an essential requirement when developing a spatial model. Before considering the local regression, it is fundamental to access the global regression statistic as it is robust and allow access to the model's performance, significance, stationarity, multicollinearity and bias. It can also verify if the independent variables are statistically significant. The OLS model explained $40 \%$ of the total variance in youth pregnancy rates. After confirming nonstationarity in the relationship among variables through the Koenker statistic, we upgraded to the GWR tool which deals precisely with this issue.

A single equation was computed for each municipality of continental Portugal. Table 2 shows the principal statistical outcomes from the GWR modelling process. Those results confirm that the local GWR approach is preferable to the global OLS model (Table 2 ). The obtained model explained $55 \%$ of births by teenage pregnancy rates variability (adjusted $\mathrm{R}^{2}$ ), which is an acceptable value considering the research field. The AICc value here was lower than the global regression model and 74 neighbours were used for each local estimation. The effective number of the parameters amounted to 56 , the residual squares value was 64 and the estimated standard deviation was 0.53 .

The GWR models the residuals-areas where over- and underestimated predictions occurred with a random distribution pattern, as shown by the Global Moran's $I$ statistic $(\mathrm{P}-\mathrm{value}=0.25)$. The residuals were mostly small, which indicates good prediction. In

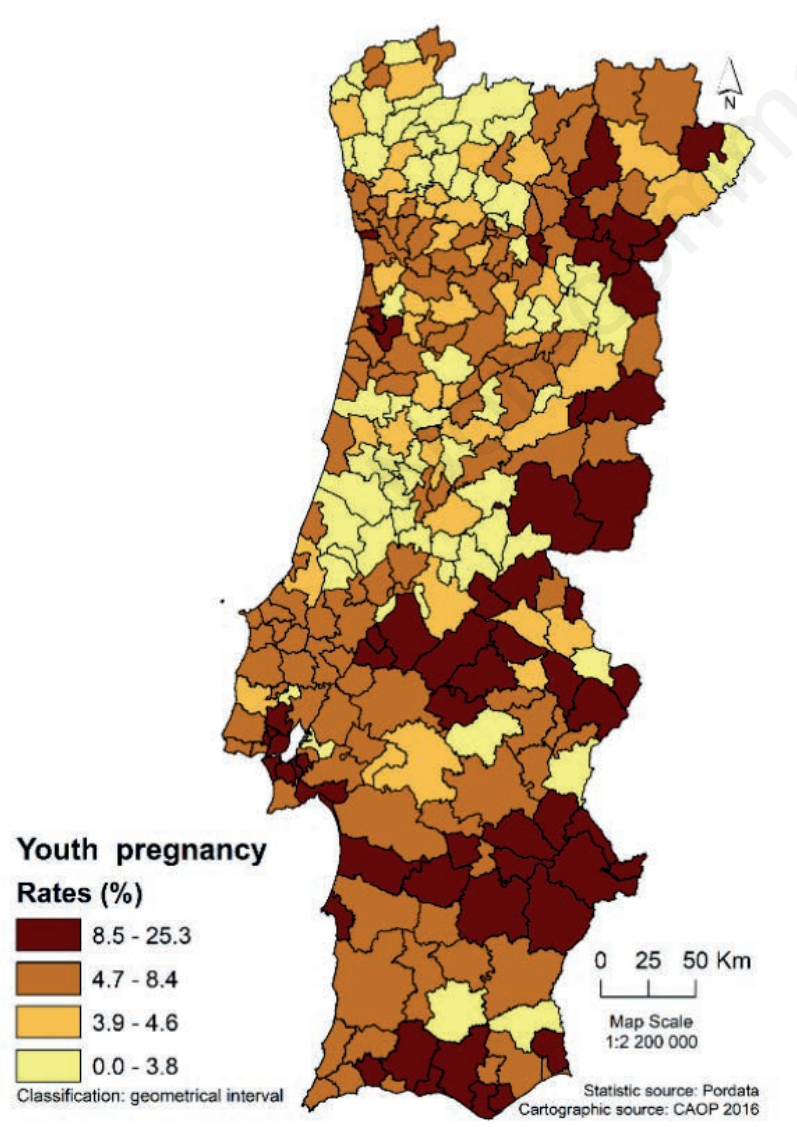

Figure 3. Youth pregnancy rates.
Table 1. Ordinary least squares diagnostics and results.

\begin{tabular}{lcc}
\hline Diagnostic & Statistic outcome & P-value \\
$\mathrm{R}^{2}$ & 0.4120 & - \\
Adjusted R & 0.4034 & - \\
\hline Akaike Information Criterion & 528.2750 & - \\
Joint Wald & 163.5644 & 0.0000 \\
\hline Jarque-Bera & 4.1870 & 0.1232 \\
Koenker & 17.9209 & 0.0012 \\
\hline Globan Moran's I & 0.2620 & 0.0000 \\
\hline Model variable & Coefficient & Robust t-value \\
\hline Intercept & -2.2840 & $-2.8098^{*}$ \\
Social Security beneficiaries & 0.2303 & $3.3675^{*}$ \\
\hline Households without amenities & 0.1170 & $6.2320^{*}$ \\
School leaving rate & 0.2375 & $3.6351^{*}$ \\
\hline Youth and female unemployment rate & 0.7111 & $4.3183^{*}$ \\
\hline *P $\leq 0.01$. & &
\end{tabular}

Table 2. Geographically weighted regression diagnostics and results.

\begin{tabular}{lcc}
\hline Diagnostic & Statistic outcome & P-value \\
$\mathrm{R}^{2}$ & 0.6376 & - \\
Adjusted R & 0.5475 & - \\
\hline Akaike Information Criterion & 486.5426 & - \\
Globan Moran's I & 0.0389 & 0.255
\end{tabular}

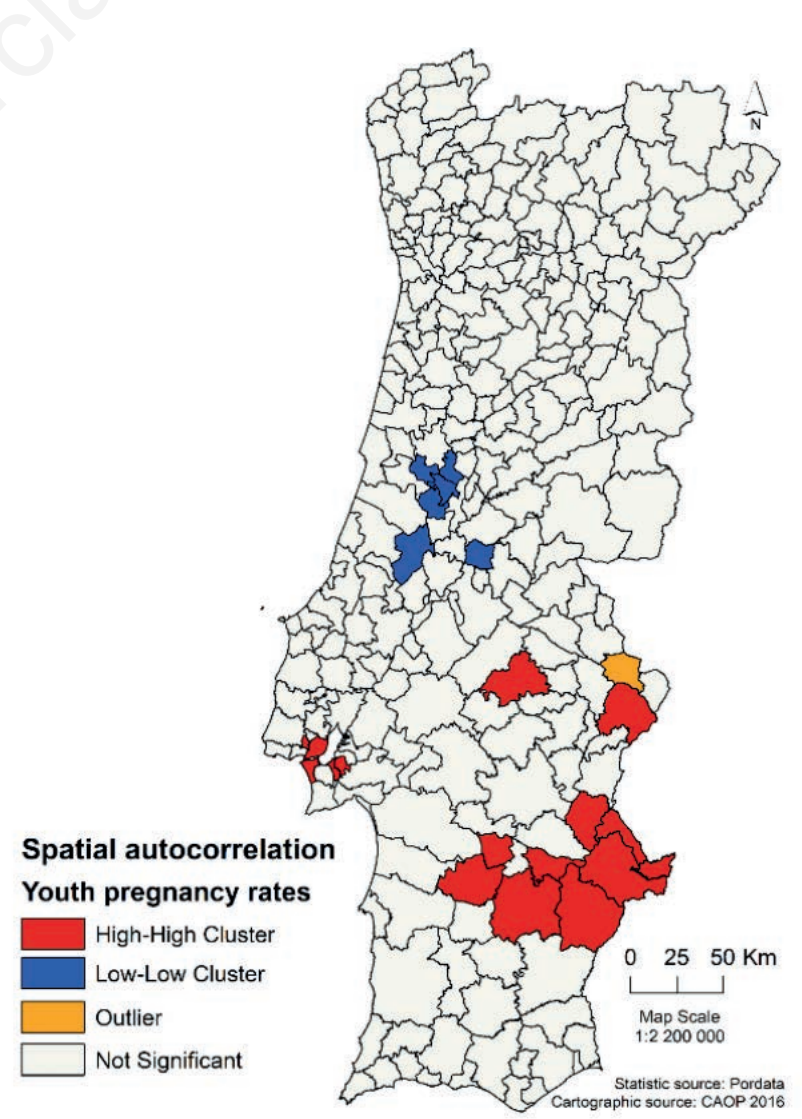

Figure 4. Local spatial autocorrelation of youth pregnancies. 
spite of a pattern increasing from the geographical South to North, there was no evidence of local multicollinearity among the predictors since the condition number values were $<15$.

The local $\mathrm{R}^{2}$ (Figure 6) was stronger for the Centre and the South, indicating that the data fit better in those regions, and weaker in the North, where the data did not fit as well. The amplitude of values, ranging from 0.06 to 0.73 , is noteworthy. To better understand the regional variation, we mapped the independent variable coefficients (Figure 7). The areas with a strong relationship between the independent variable and youth pregnancy rates are shown in red. The darker the shade, the stronger the association. The geographical distribution of the variables Social Security beneficiaries and households without amenities are somewhat similar in showing a strong association in the South. However, the latter shows a separate area on the middle of the west coast, repeated just slightly further south by the variable youth and female unemployment that does not have any further strong relationships. The variable concerning those leaving school prematurely is completely different, with strong associations only in the North. The maps illustrate the geographical fluctuation of the various relationships and visualizes where changing the independent variables would have the most effect on youth pregnancy rates, and where each variable is important.

The variation of the coefficients variables also shows the strength of the spatial patterns. The Social Security beneficiaries had a big impact in a large portion of the territory, specifically in the central South, while a strong negative relationship was found in the interior of the northern region. The coefficient of households without amenities was higher in the Centre and in the South with a lower impact in the rest of the country. It is important to notice that this is the only explanatory variable from the model that did not keep a negative relationship with the dependent variable. Leaving school prematurely had the strongest effect on youth pregnancy rates in the North and in the interior of continental Portugal. Finally, youth and female unemployment had a durable impact along the central western coast, but it was possible to verify a medium impact of this variable across all regions of the study area. This notwithstanding, a strong negative relationship was found in some of the municipalities located in the South.

\section{Discussion}

This study highlights an important health topic in Portugal by bringing in spatial variation as a fundamental factor to understand the distribution of youth pregnancy. Although we identified clusters in various places, they were particularly prominent in several municipalities located in the Lisbon metropolitan area and in the South of Portugal. Special attention should be taken as youth pregnancy rates were stronger in these areas due to the geographical features as pointed by the regression results and by inspecting area coefficients. Health authorities, social security, private social soli-

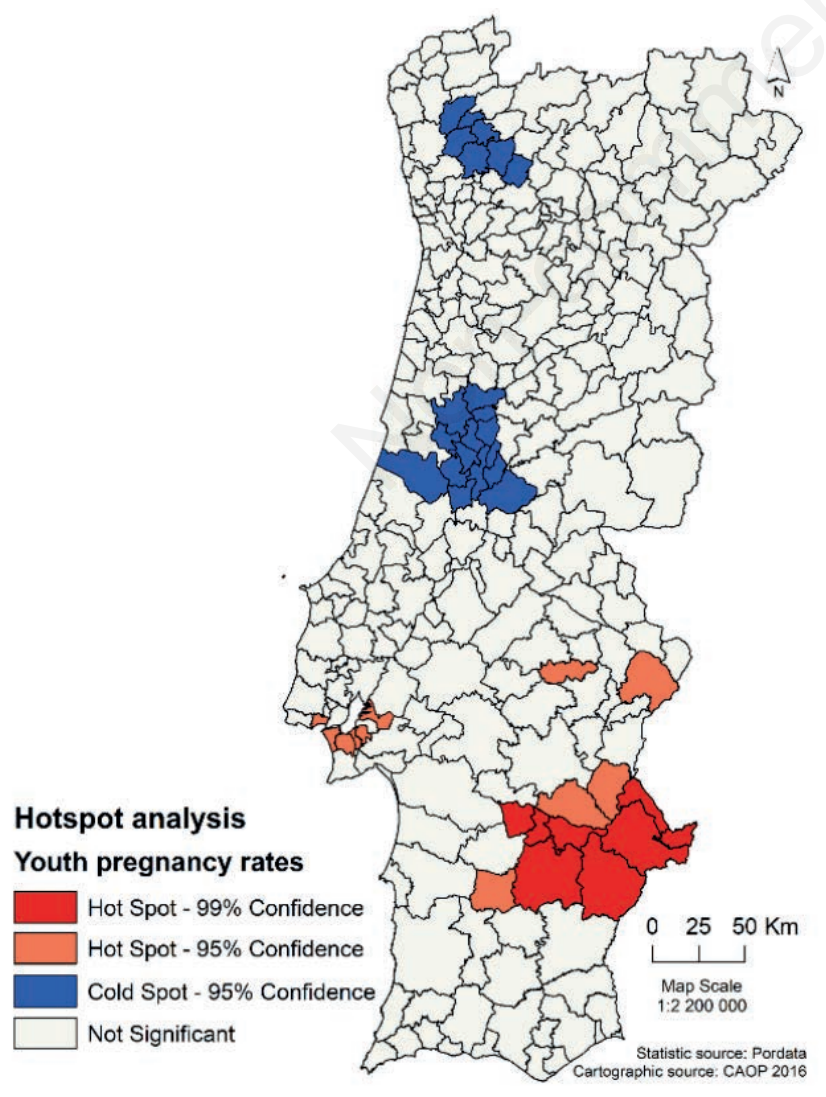

Figure 5. Youth pregnancy hotspot analysis.

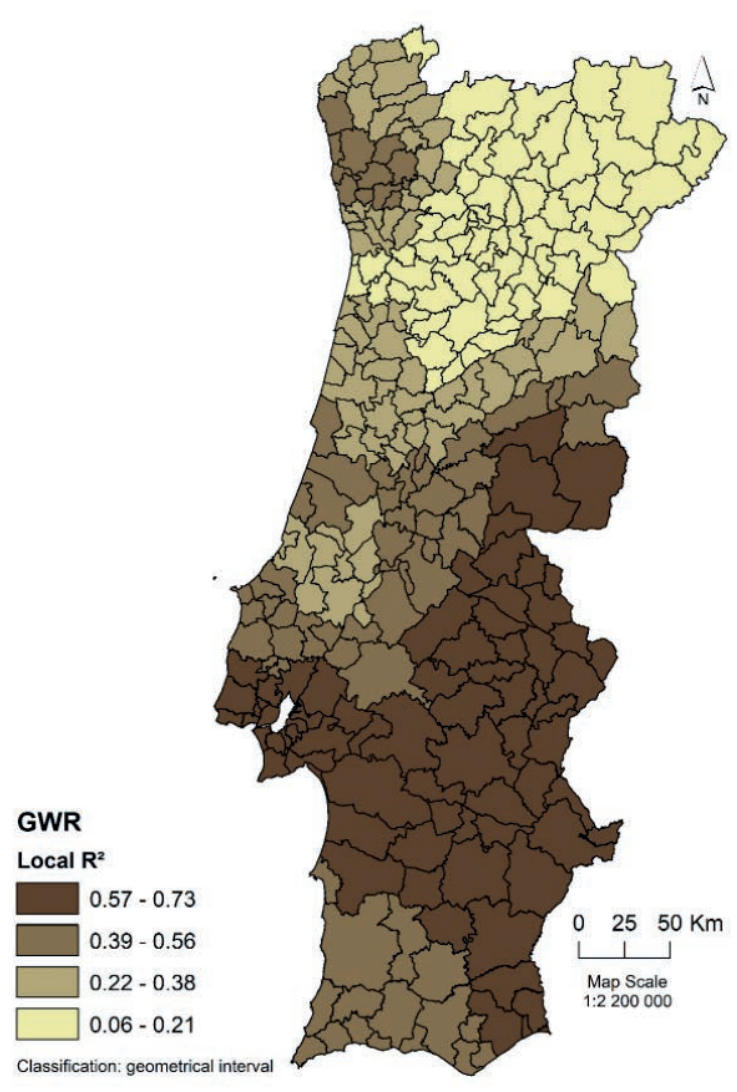

Figure 6. Geographically weighted regression (GWR) local $R^{2}$. 
darity institutions, schools and local authorities should define interventions and target efforts to tackle the problem, for instance, by implementing strategic and directional programmes where they would have the greatest impact.

Transitioning from global to local regression, allowing the

$\mathbf{A}$

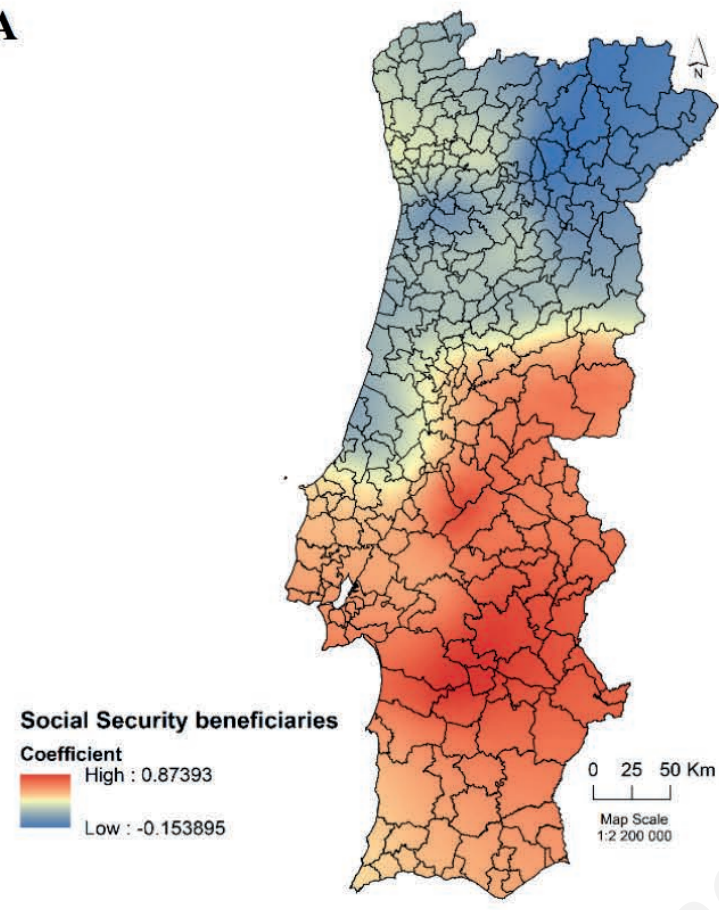

C

School leavers

Coefficient

High : 0.511013

Low : -0.0287975

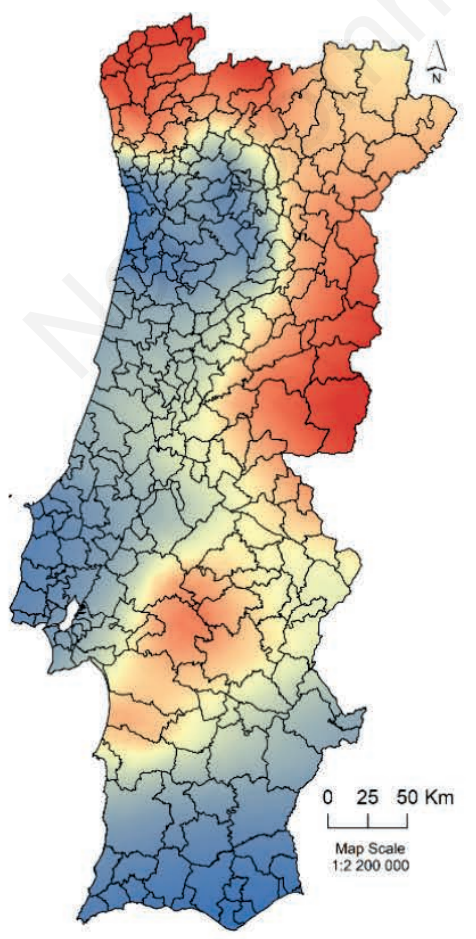

relationships varying across space, improved the results and consequently also the model. For example, GWR diagnosed a lower AICc and a higher adjusted $\mathrm{R}^{2}$, which confirms that a local approach is indeed suitable to study this phenomenon. Although not as robust as GWR, OLS was essential in identifying the vari-

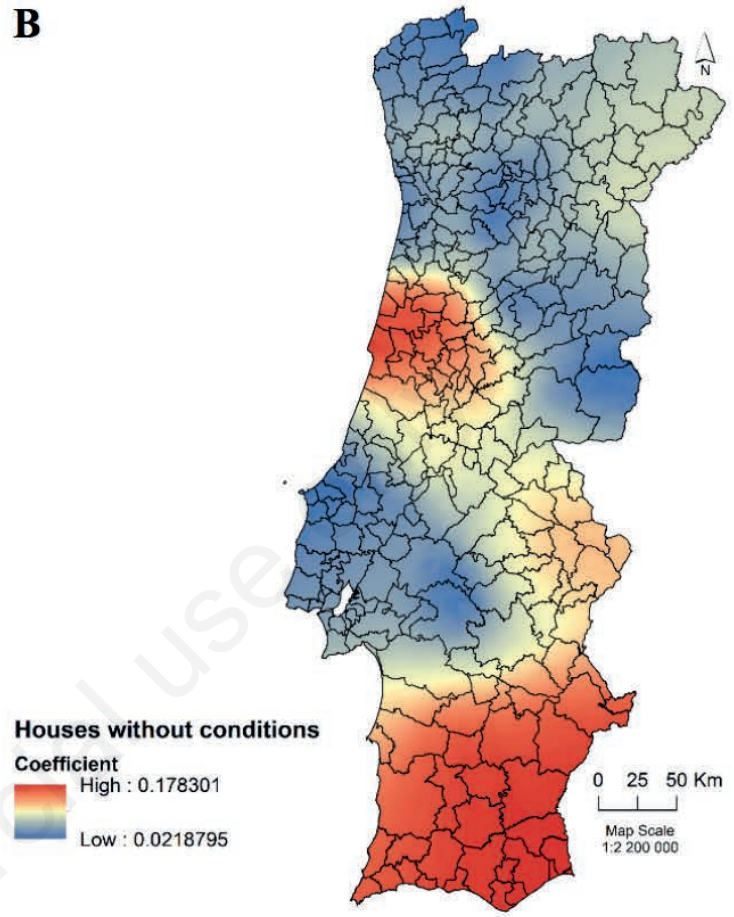

D

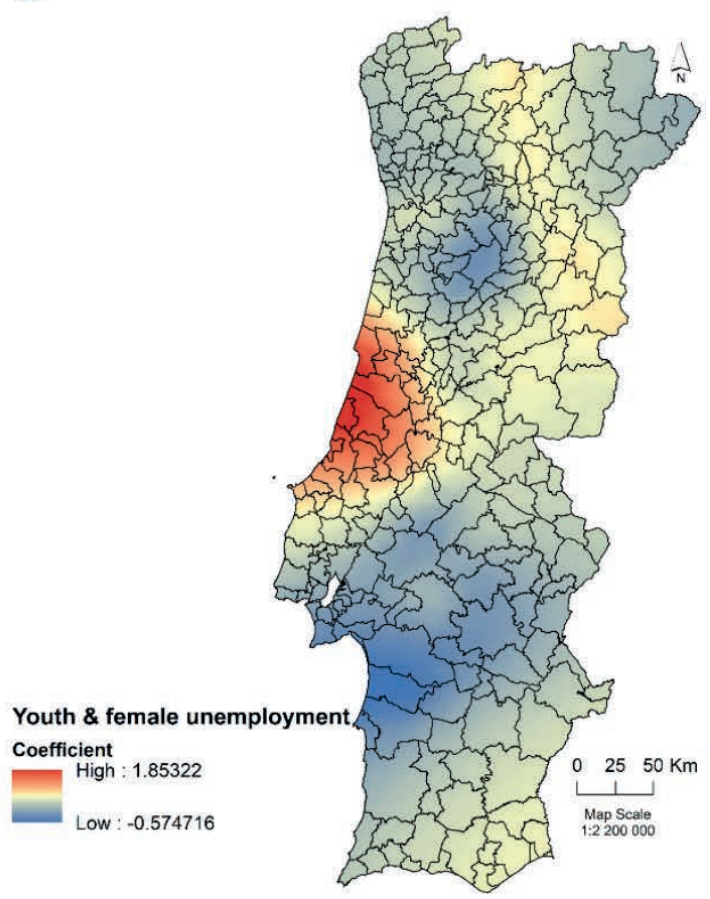

Figure 7. Geographically weighted regression coefficients. (A) Social security beneficiaries; (B) houses without conditions; (C) school leavers; (D) youth and female unemployment. 
ables explaining youth pregnancy rates, as well validating the model. It is important to notice that 3 out of the 4 variables introduced showed a positive association in some areas and a negative one in others. The relationships between youth pregnancy rates and all independent variables investigated were non-stationary and statistically significant. Social Security beneficiaries and Households without amenities appeared to better explain the high rates in the municipalities located in the Lisbon metropolitan area and in the South. The model gave the school leaving rate as the strongest cause for the high rates of youth pregnancy in the interior Centre and North. Equally, reducing youth and female unemployment rates would possibly also reduce youth pregnancy rates in almost all the regions. To improve and prevent teenage childbearing, investing in educational programmes as well as motivating and supporting students at school would be important measures. Likewise, reducing social and economic disparities and assuring good household conditions would also affect the rates positively as predicted by the model. As reflected by GWR, implementing certain measures in certain municipalities would be fundamental to avoid teenage pregnancy. Specifically, the risk of high teenage pregnancy rates are enhanced in areas with few social opportunities, less employment opportunities for females (and for youngsters in general), where families are economically disadvantaged and where dwellings do not include basic and indispensable amenities. Prevention programs targeting teenagers must be precise in admitting their needs, and they should also implement racial, ethnic, cultural and, most of all, regional differences (Berry et al., 2000; Santelli et al., 2000).

The GeoHealthS project, mentioned in the introduction, evaluates the status of health in the Portuguese population in the last 20 years using key indicators. At first sight, we noticed that the neonatal mortality of babies with low weight occurred in municipalities with higher than average youth pregnancy rates. If the data could be further disaggregated, e.g., using the parish level, or collected from additional sources, such as non-governmental organizations, the analysis results could be reinforced. The same applies for important indicators that could not be measured for this study, such as the average wedding age, the rate of babies born extramaritally, ethnicity, material deprivation, access to health care, rate of singleparents, distance to family planning clinics/programmes, drugs and/or alcohol abuse as well as contraceptive use. Creating indexes such as female and socioeconomic disadvantage could be benefit the analysis. Additionally, we did not consider variables reflecting individual attitudes, which could be determinants of teenage sexual health, including pregnancy (Haldre et al., 2009). The local $\mathrm{R}^{2}$ low values in the northern region may indicate that an important variable could be missing from the regression model. GWR can also be used to predict the impact that changes in the explanatory variables values might have on reducing youth pregnancy rates. Finally, the study excluded the Portuguese islands, which in the case of Azores, could have had an important impact on the results as youth pregnancy is common in this area (Pedrosa, 2009). Recognizing the first law of geography introduced by Waldo Tobler that everything is related to everything else, but near things are more related than distant things (Tobler, 1970), it would be interesting to further study those regions, but that would best be done separately.

GWR weaknesses are well documented in previous studies. For instance, potential problems may arise as the coefficients can demonstrate strong positive spatial autocorrelations (Griffith,
2008), or they can be correlated even when there is no collinearity among variables (Wheeler and Tiefelsdorf, 2005; Griffith, 2008). In fact, it is unclear which tests can reliably diagnose model problems. This notwithstanding, we followed a methodological path that can be useful to others wanting to implement GWR to study health spatial problems. The results further suggest a notable social, demographic and economic imbalance that connects and explains youth pregnancy rates in the country as suggested by our model. GWR is an exploratory technique that enables the understanding of these relationships and how they vary across continental Portugal. Although the results obtained are statistically sound, the relevance of this kind of modelling requires special attention and care to avoid the misinterpretation of false spatial patterns (Wheeler and Tiefelsdorf, 2005). Thus, additional research is needed to complement our findings.

\section{Conclusions}

In this study, we underline that social, economic and geographic conditions are directly associated with adolescent parenthood rates in the country. Using GWR, we present the first national study for youth pregnancy patterns in continental Portugal at the municipality level. Local regression allowed us to identify, measure and interpret spatial patterns and relationships among geographically changing variables that can be hidden or unknown. We found that teenage pregnancies rates can be explained by variables, such as Social Security beneficiaries; the number of households without amenities; the rate of pupils leaving school prematurely; as well as youth and female unemployment rates, ceteris paribus. It was also found that Social Security beneficiaries have a high impact in the Centre and South of the country; that households without amenities have a stronger impact in the middle of the west coast and in the South than elsewhere; that the influence of the rate of leaving school prematurely is particularly deep along the northern border with Spain; and that youth and female unemployment rates are particularly noticeable in the Centre. Hence, we not only identified which factors may contribute to higher youth pregnancy rates, but also showed why some factors are more important than others in certain locations, as suggested by the coefficient maps. Our findings may offer meaningful information on where and how to focus to reduce teenage pregnancy rates. Different interventions to prevent and reduce those rates may be then taken in different areas. In the same way that Pires et al. recognized the importance to attend to the regional heterogeneity (Pires et al., 2013), our study reinforces the crucial need to approach youth pregnancy attending the spatial diversity and features that may influence higher rates, as revealed by the model. Even if GWR provided helpful information by taking into account the spatial heterogeneity of the relationships between youth pregnancy rates and the explanatory variables, there were certain unexplained variations that should be investigated. Thus, our investigation should be useful to identify, report and understand the national context and progress towards SDG number 3, in particular target 3.7, i.e. by 2030, ensure universal access to sexual and reproductive healthcare services, including for family planning, information and education, and the integration of reproductive health into national strategies and programmes (United Nations General Assembly, 2015). 


\section{References}

Akaike H, 1974. A new look at the statistical model identification. IEEE Trans Automat Contr 19:716-23.

Amin R, Decesare JZ, Hans J, Roussos-Ross K, 2017. Epidemiologic surveillance of teenage birth rates in the United States, 2006-2012. Obstet Gynecol 129:1068-77.

Anselin L, 1995. Local indicators of spatial association - LISA. Geogr Anal 27:93-115.

Araújo Pedrosa A, Pires R, Carvalho P, Canavarro MC, Dattilio F, 2011. Ecological contexts in adolescent pregnancy: the role of individual, sociodemographic, familial and relational variables in understanding risk of occurrence and adjustment patterns. Contemp Fam Ther 33:107-27.

Azevedo WF, Diniz MB, Fonseca ESVB, Azevedo LMR, Evangelista CB, 2015. Complications in adolescent pregnancy: systematic review of the literature. Einstein (São Paulo) 13:618-26.

Baker P, Guthrie K, Hutchinson C, Kane R, Wellings K, 2007. Teenage pregnancy and reproductive health. RCOG Press, London, UK.

Berry EH, Shillington AM, Peak T, Hohman MM, 2000. Multi-ethnic comparison of risk and protective factors for adolescent pregnancy. Child Adolesc Soc Work J 17:79-96.

Bersamin M, Todd M, Remer L, 2011. Does distance matter? Access to family planning clinics and adolescent sexual behaviors. Matern Child Health J 15:652-9.

Birungi H, Undie C-C, MacKenzie I, Katahoire A, Obare F, Patricia M, 2015. Education sector response to early and unintended pregnancy: a review of country experiences in SubSaharan Africa, STEP UP and UNESCO Research Report. Available from: https://www.popcouncil.org/.../2015STEPUP EducSectorResp.pdf

Blake BJ, Bentov L, 2001. Geographical mapping of unmarried teen births and selected sociodemographic variables. Public Health Nurs 18:33-9.

Brunsdon C, Fotheringham S, Charlton M, 1998. Geographically weighted regression. J R Stat Soc Ser D (The Stat) 47:431-43.

ChildTrends, 2016. Child Trends Databank. Teen pregnancy. Available from: https://www.childtrends.org/?indicators=teenpregnancy. Accessed: August 22, 2017.

Christoffersen M, Azhar H, 2008. Teenage pregnancies: consequences of poverty, ethnic background, and social conditions. Social Forksnings Instituttet, Copenhagen, Denmark.

Coelho FM da C, Pinheiro RT, Silva RA, Quevedo L de Á, Souza LD de M, Castelli RD, Matos MB, Pinheiro KAT, 2013. Major depressive disorder during teenage pregnancy: socio-demographic, obstetric and psychosocial correlates. Rev Bras Psiquiatr 35:51-6.

Cook SMC, Cameron ST, 2015. Social issues of teenage pregnancy. Obstet Gynaecol Reprod Med 25:243-8.

Costa C, Loureiro A, Santana P, Cardoso G, Ferrão J, 2015. Suicide, economic crisis and material deprivation in Portugal in the last 20 years. Eur J Public Health 25:ckv171.053.

Cross Cutting Issues Technical Working Group (CCITWG), 2009. Guidelines on how to enable pregnant school girls to continue with their studies. Cross Cutting Issues Technical Working Group, Ministry of Education and Vocational Training, Tanzania. Available from: www.tzdpg.or.tz/...working_ groups.../education/Guidelines_Enabling_Pregnant_Girls_to_r e-enter school-FINAL March 2010.pdf
Daniels JP, 2015. Tackling teenage pregnancy in Colombia. Lancet 385:1495-6.

Darroch JE, Singh S, 1999. Why is teenage pregnancy declining? The roles of abstinence, sexual activity and contraceptive use. Occasional Report No. 1. Guttmacher Institute. Available from: https://www.issuelab.org/resource/why-is-teenage-pregnancy-declining-the-roles-of-abstinence-sexual-activity-andcontraceptive-use.html

Decker MR, Kalamar A, Tunçalp Ö, Hindin MJ, 2016. Early adolescent childbearing in low- and middle-income countries: associations with income inequity, human development and gender equality. Health Policy Plan 32:277-82.

ESRI, 2017. ArcGIS. Available from: https://desktop.arcgis.com/ en/arcmap/

Fenn N, Edmeades J, Lantos H, Onovo O, 2015. Child marriage, adolescent pregnancy and family formation in West and Central Africa. UNICEF West and Central Africa Regional Office, Dakar, Senegal. Available from: https://www.unicef. org/wcaro/english/Child_Mariage_Adolescent_Pregnancy_an d Family Formation in WCA.pdf.

Figueiredo B, Pacheco A, Magarinho R, 2005. Grávidas adolescentes e grávidas adultas diferentes circunstâncias de risco? Acta Med Port 18:97-105.

Figueiredo B, Pacheco A, Costa R, Magarinho R, 2006a. Adolescent pregnancy: from risk circumstances to circumstances that beneficiate pregnancy adaptation. Int $\mathrm{J}$ Clin Heal Psychol 6:97-125.

Figueiredo B, Bifulco A, Pacheco A, Costa R, Magarinho R, 2006b. Teenage pregnancy, attachment style, and depression: A comparison of teenage and adult pregnant women in a Portuguese series. Attach Hum Dev 8:123-38.

Figueiredo B, Tendais I, Dias CC, 2014. Maternal adjustment and maternal attitudes in adolescent and adult pregnant women. $\mathrm{J}$ Pediatr Adolesc Gynecol 27:194-201.

Fonseca L, Almeida Santos S, 2015. Sexualidades, gravidez e juventude: relações sociais e educativas. Afrontamento, Porto, Portugal.

Fonseca L, Araújo HC, Santos SA, 2012. Sexualities, teenage pregnancy and educational life histories in Portugal: experiencing sexual citizenship? Gend Educ 24:647-64.

Fotheringham AS, Brunsdon C, Charlton ME, 2002. Geographically weighted regression: The analysis of spatially varying relationships. Wiley, New York, USA.

Fronteira I, Oliveira da Silva M, Unzeitig V, Karro H, Temmerman M, 2009. Sexual and reproductive health of adolescents in Belgium, the Czech Republic, Estonia and Portugal. Eur J Contracept Reprod Heal Care 14:215-20.

Griffith DA, 2008. Spatial-filtering-based contributions to a critique of Geographically Weighted Regression (GWR). Environ Plan A 40:2751-69.

Guterman K, 2015. Unintended pregnancy as a predictor of child maltreatment. Child Abuse Negl 48:160-9.

Haldre K, Rahu K, Rahu M, Karro H, 2009. Individual and familial factors associated with teenage pregnancy: an interview study. Eur J Public Health 19:266-70.

Harden A, Brunton G, Fletcher A, Oakley A, Burchett H, Backhans M, 2006. Young people, pregnancy and social exclusion: A systematic synthesis of research evidence to identify effective, appropriate and promising approaches for prevention and support. EPPI-Centre, Social Science Research Unit, Institute of Education, University of London, London, UK. 
Imamura M, Tucker J, Hannaford P, da Silva MO, Astin M, Wyness L, Bloemenkamp KWM, Jahn A, Karro H, Olsen J, Temmerman M, 2007. Factors associated with teenage pregnancy in the European Union countries: a systematic review. Eur J Public Health 17:630-6.

Instituto National de Estatistica (INE), 2011. XV Recenseamento Geral da População. Lisboa, Portugal. Available from: https://www.ine.pt/xportal/xmain?xpid=INE\&xpgid=ine_pesq uisa\&frm_accao $=$ PESQUISAR\&frm_show_page_num $=1 \& \mathrm{fr}$ $m$ modo pesquisa $=$ PESQUISA SIMPLES\&frm texto $=$ censos+2011\&frm_modo_texto=MODO_TEXTO_ALL\&frm_da ta_ini $=\&$ frm_data_fim $=\&$ frm_tema $=$ QUALQUER_TEMA \&f $\mathrm{rm} \_$area $=0$ ine_area_Publicacoes\&xlang $=\mathrm{pt}$

Ivajnšič D, Kaligarič M, Žiberna I, 2014. Geographically weighted regression of the urban heat island of a small city. Appl Geogr 53:341-353.

Jarque CM, Bera AK, 1980. Efficient tests for normality, homoscedasticity and serial independence of regression residuals. Econ Lett 6:255-9.

Jarque CM, Bera AK, 1987. A test for normality of observations and regression residuals. Int Stat Rev 55:163-72.

Koenker R, 1981. A note on studentizing a test for heteroscedasticity. J Econom 17:107-12.

Kohler PK, Manhart LE, Lafferty WE, 2008. Abstinence-only and comprehensive sex education and the initiation of sexual activity and teen pregnancy. J Adolesc Heal 42:344-51.

Leftwich HK, Alves MVO, 2017. Adolescent pregnancy. Pediatr Clin North Am 64:381-8.

Lindberg L, Santelli J, Desai S, 2016. Understanding the decline in adolescent fertility in the United States, 2007-2012. J Adolesc Heal 59:577-83.

Longley P, Batty M, 1996. Local spatial statistics: an overview. John Wiley \& Sons, New York, USA. pp 261-278.

Manikandan S, 2010. Data transformation. J Pharmacol Pharmacother 1:126.

Maravilla JC, Betts KS, Couto e Cruz C, Alati R, 2017. Factors influencing repeated teenage pregnancy: a review and metaanalysis. Am J Obstet Gynecol 217:527-45.e31.

Martinez EZ, Roza DL da, Caccia-Bava M, do CGG Achcar JA, Dal-Fabbro AL, 2011. Gravidez na adolescência e características socioeconômicas dos municípios do Estado de São Paulo, Brasil: análise espacial. Cad Saude Publica 27:855-67.

Mendes N, Castelo-Branco C, 2014. Adolescent pregnancy in Portugal. In: Cherry AL, Dillon ME, eds. International handbook of adolescent pregnancy. Springer US, Boston, MA, USA. pp 523-534.

Mendes N, Palma F, Serrano F, 2014. Sexual and reproductive health of Portuguese adolescents. Int J Adolesc Med Health 26:3-12.

Miranda MJ de, Costa C, Santana P, Barrozo LV, 2014. Associação espacial entre variáveis socioeconômicas e risco relativo de nascimentos pré-termo na Região Metropolitana de São Paulo (RMSP) e na Área Metropolitana de Lisboa (AML). Saúde Soc 23:1142-53.

Mitchell A, 2005. The ESRI Guide to GIS analysis, volume 2. ESRI Press, Redlands, CA, USA.

Nkosha C, Luchembe M, Chakufyali PN, 2013. Girl-child education campaigns and enrolment/retention in Zambian basic schools: impact analysis. J Int Coop Educ 15:113-33.

Odgers CL, Caspi A, Nagin DS, Piquero AR, Slutske WS, Milne BJ, Dickson N, Poulton R, Moffitt TE, 2008. Is it important to prevent early exposure to drugs and alcohol among adolescents? Psychol Sci 19:1037-44.

Panova OV, Kulikov AM, Berchtold A, Suris JC, 2016. Factors associated with unwanted pregnancy among adolescents in Russia. J Pediatr Adolesc Gynecol 29:501-5.

Pedrosa AA, 2009. Gravidez e transição para a maternidade na adolescência determinantes individuais e psicossociais da ocorrência de gravidez e da adaptação. Estudo com adolescentes da Região Autónoma dos Açores. University of Coimbra, Coimbra, Portugal.

Pires R, Pereira J, Araújo-Pedrosa A, Bombas T, Vilar D, Vicente L, Canavarro MC, 2013. Trajetórias reprodutivas na origem da gravidez na adolescência: Um estudo representativo da realidade nacional e regional portuguesa. In: Pereira A, Calheiros M, Vagos P, Direito I, Monteiro S, da Silva CF, Gomes AA, eds. Atas do VIII Simpósio Nacional de Investigação em Psicologia. Associação Portuguesa de Psicologia, Lisbon, Portugal. pp 158-168.

Pires R, Araújo-Pedrosa A, Pereira J, Canavarro MC, 2014. Preventing adolescent pregnancy: biological, social, cultural, and political influences on age at first sexual intercourse. J Prim Prev 35:239-54.

Roquette R, Painho M, Nunes B, 2017. Spatial epidemiology of cancer: a review of data sources, methods and risk factors. Geospat Health 12:23-35.

Rowlands S, 2010. Social predictors of repeat adolescent pregnancy and focussed strategies. Best Pract Res Clin Obstet Gynaecol 24:605-16.

Roza DL da, Martinez EZ, 2015. Spatial distribution of pregnancy in adolescence and associations with socioeconomic and social responsibility indicators: State of Minas Gerais, Southeast of Brazil. Rev Bras Ginecol Obs 37:366-73.

Santana P, Costa C, Cardoso G, Loureiro A, Ferrão J, 2015. Suicide in Portugal: spatial determinants in a context of economic crisis. Health Place 35:85-94.

Santana P, Costa C, Loureiro A, Raposo J, Boavida JM, 2014. Geografias da diabetes mellitus em Portugal: Como as condições do contexto influenciam o risco de morrer. Acta Med Port 27:309.

Santelli JS, Lowry R, Brener ND, Robin L, 2000. The association of sexual behaviors with socioeconomic status, family structure, and race/ethnicity among US adolescents. Am J Public Health 90:1582-8.

SAS Institute, 2010. SAS/STAT ${ }^{\circledR} 9.22$ User's guide. Available from: support.sas.com/.../cdl/en/statugwhatsnew/.../statugwhatsnew.pdf

Shartzer A, Courtot B, McMorrow S, Benatar S, Kenney G, 2016. Knowledge gaps and misinformation about birth control methods persist in 2016. Health, Women/Girls. Available from: https://www.urban.org/research/publication/knowledge-gapsand-misinformation-about-birth-control-methods-persist-2016

Shoff C, Yang T-C, 2012. Spatially varying predictors of teenage birth rates among counties in the United States. Demogr Res 27:377-418.

Shoff C, Yang T-C, Matthews SA, 2012. What has geography got to do with it? Using GWR to explore place-specific associations with prenatal care utilization. Geo J 77:331-41.

Siegel RS, Brandon AR, 2014. Adolescents, pregnancy, and mental health. J Pediatr Adolesc Gynecol 27:138-50.

Singh S, Darroch J, 2000. Adolescent Pregnancy and childbearing: levels and trends in developed countries. Fam Plann Perspect 32:14. 
Singh S, Darroch J, Frost J, 2001. Socioeconomic disadvantage and adolescent women's sexual and reproductive behavior: The case of five developed countries. Fam Plann Perspect 33:251-89.

Singh S, Remez L, Sedgh G, Kwok L, Onda T, 2018. Abortion worldwide 2017: uneven progress and unequal access. Guttmacher Institute, New York, USA.

Sipsma HL, Ickovics JR, Lewis JB, Ethier KA, Kershaw TS, 2011. Adolescent pregnancy desire and pregnancy incidence. Womens Health Issues 21:110-6.

Su S, Li D, Hu Y, Xiao R, Zhang Y, 2014. Spatially non-stationary response of ecosystem service value changes to urbanization in Shanghai, China. Ecol Indic 45:332-9.

Thompson SJ, Bender KA, Lewis CM, Watkins R, 2008. Runaway and pregnant: risk factors associated with pregnancy in a national sample of runaway/homeless female adolescents. J Adolesc Heal 43:125-32.

Tobler W, 1970. A computer movie simulating urban growth in the Detroit region. Econ Geogr 46:234-40.

UNICEF, 2004. Strategies for girls' education. Available from: https://www.unicef.org/publications/index_21345.html.

United Nations Populations Fund (UNFPA), 2013. The state of world population: motherhood in childhood - Facing the challenge of adolescent pregnancy. Available from: https://www. unfpa.org/publications/state-world-population-2013.
United Nations General Assembly, 2015. Transforming our world: the 2030 Agenda for sustainable development. Gen Assem 70 Sess. Available from: https://doi.org/10.1007/s13398-0140173-7.2.

Wald A, 1943. Tests of statistical hypotheses concerning several parameters when the number of observations is large. Trans Am Math Soc 54:426.

Wall-Wieler E, Roos LL, Nickel NC, 2016. Teenage pregnancy: the impact of maternal adolescent childbearing and older sister's teenage pregnancy on a younger sister. BMC Pregnancy Childbirth 16:120.

Washington State Department of Health, 2014. Teen pregnancy and childbearing. Available from: https://www.doh. wa.gov/Portals/1/Documents/1500/MCH-TPC2014.pdf.

Wheeler D, Tiefelsdorf M, 2005. Multicollinearity and correlation among local regression coefficients in geographically weighted regression. J Geogr Syst 7:161-87.

World Health Organization (WHO), 2005. Nutrition in adolescence: issues and challenges for the health sector issues in adolescent health and development. WHO, Geneva, Switzerland.

World Health Organization (WHO), 2014. Adolescent pregnancy. WHO, Geneva, Switzerland. Available from: https://www. who.int/news-room/fact-sheets/detail/adolescent-pregnancy 